\title{
Heat Transfer Enhancement Through Perforated Fin
}

\author{
Noaman Salam, Khan Rahmatullah, Faizanurrahman, Salman Ah, \\ Ansari Tohid, Tarique Khan \\ (Department of Mechanical Engineering, MMANTC Malegaon, India)
}

\begin{abstract}
Enhancement of heat transfer rate and reduction of fin dimension has major criteria in designing of heat exchanger components. This project is an experimental analysis to investigate forced heat transfer of rectangular fin by comparing both solid and circular perforation along the lateral axis of the fin. Performance is analyzed experimentally by designing experimental setup for specific fin length. Thermal performance, effectiveness and pressure drop reduction. Due to increase in surface area or convective area heat transfer rate increases, pressure drop reduces, Nusselt Number increases. The large impact is that higher reduction in weight of fin is achieved by producing perforation which is the major requirement in heat transfer equipment.
\end{abstract}

Keywords : Effectiveness, Enhancement, Fin length, Nusselt number, Perforation, Rectangular fin.

\section{Introduction}

Fins are extended surfaces which are good heat transfer equipment that are widely used for various industrial applications. Due to high demand for lightweight, compact, and economical fins, the optimization of fin size is of great importance. Performance of three dimensional rectangular fins has been studied extensively by many investigators. Pressure drag co-efficient and pressure drop due to perforation are also considered as these parameters are responsible for the effective and efficient cooling performance of heat sinks. For this consideration, laminar fluid flow and convective heat transfer around an array of solid and perforated fins are analyzed practically. Fins having five perforations circular cross sections are investigated. These perforations are along the fin and their cross section is perpendicular to the fluid flow direction. In this study, the improvement in heat transfer coefficient, other thermal and hydraulic attributes of rectangular fin arrays with circular perforation has been investigated under laminar flow condition. Heat sink performance can be evaluated by several factors: material, surface area, fin configuration, pumping power and fan requirements. To obtain higher performance from a heat sink, more surface area, less weight, and lower cost are necessary. Thus, efforts to obtain more optimized designs for heat sinks are needed to achieve high thermal performance. Most of the previous studies on pin fins or parallel plate fin heat sinks have considered the geometric configurations of the fins such as shape, size or orientations. The study considers the benefits of perforating the pins with rectangular slot or notch perforations and shows that both of these can provide significantly enhanced rates of heat transfer while simultaneously reducing the fan power required to create the air motion over the heat sink, compared to corresponding solid pins.

An interesting application of fins from about 150 million years ago, the Jurassic era the dinosaur stegosaurus lived during this era and it had two rows of big (and bizarre) bony plates down its back. For a long time, scientist thought that the plates were some kind of armor to protect the vegetarian from predators. We now know that a lot of blood flowed through the plates, and they may have acted like a car radiator. The heart pumped blood through the plates, and the plates acted like cooling fins to cool the blood down [1]. Mehedi ehteshum ,musa tabassum et. al. (2015) [2] conducted test on different Reynolds number effects to test the heat transfer enhancement. They tested five different types of fins to observe different parameters like nusselt number, heat transfer coefficient and pressure drop with increasing Reynolds number for all fins. And stated that perforated fins are higher value of heat transfer coefficient and nusselt number and lower value of pressure drop. Decreasing the perforation dimension reduces the rate of temperature drop along the perforated fin. Heat transfer coefficient for perforated fin that contained a larger number of perforations higher than the perforated fin that contained a small number of perforations. It is believed that comparing the perforated fins with its solid compartment is the best means to evaluate improvement or non-improvement in heat transfer brought about by introducing the perforations. Md. Farhad Ismail et. al. [3] has studied on the heat transfer enhancement in longitudinal perforated fins that perforated fins has the higher surface contact area, minimum pressure drop, more effectiveness. It is found that circular and square fins are almost the same amount of heat removal rate, but circular perforated fins have significantly less pressure drop. He used the computational fluid domain for his research and analysis of heat transfer equipments have been required to be much more compact in size and light in weight because of space limitation. While a simple solid baffle plate attached to the duct wall enhances heat 
transfer, a perforated plate attached to the same duct has a better performance. Shaeri et. al. [4] in his numerical analysis of three-dimensional numerical study of turbulent fluid flow and convective heat transfer over an array of solid and perforated fins are performed. He found that perforated fins have higher contact area with fluid in comparison with solid fin. So the average friction drag for perforated fins is lower compared to solid fin and also it increases by adding perforations. By increasing number of perforations, the size of formed wake behind the fin decreased. Accordingly the form drag for solid fin is the highest and it decreases with increase of perforations. By increasing number of perforations, the length of recirculation zone around the lateral surfaces of fin reduced. In fact solid fin has the largest recirculation zone at its lateral surfaces. Temperature drop from fin base to fin top surface increases with addition of perforations. For fins with perforation, drag force reduces. Also drag ratio becomes smaller by increasing Reynolds number. Fins with the same porosity but larger window sizes have higher Nusselt number than fin with smaller windows. By increasing number of perforations, temperature difference between the fin base and fin tip becomes larger. By making window perforations and especially with increasing number of perforations, lighter fins that are more economical achieved. A.Aldamook et. al. [5] suggests results conducted by computational fluid dynamics and optimization that the heat transfer rate increases upto the $10 \%$ with perforated fins compare to solid fins. Perforation reduces the fan power and pressure drop in during flow with $30 \%$ and $40 \%$ respectively. He also suggested that density influences the heat transfer rate. The advantage of cutting notches from the top of the pins is that no pre-processing of the pins is required from an existing heat sink either wire Electrical Discharge Machining could be used to directly cut into the notches. The denser the pin greater the heat transfer rate due to conduction heat transfer. However, the reduced manufacturing complexity of rectangular notched pins in particular provides strong motivation for their use in practical applications.

a. Fins:

\section{Theoratical Background}

Fins are nothing but the extended area to increase the convective heat transfer rate. By Newton's law of cooling the convective heat transfer rate is directly proportional to normal area to flow of fluid. Hence by increasing area heat transfer rate increases.

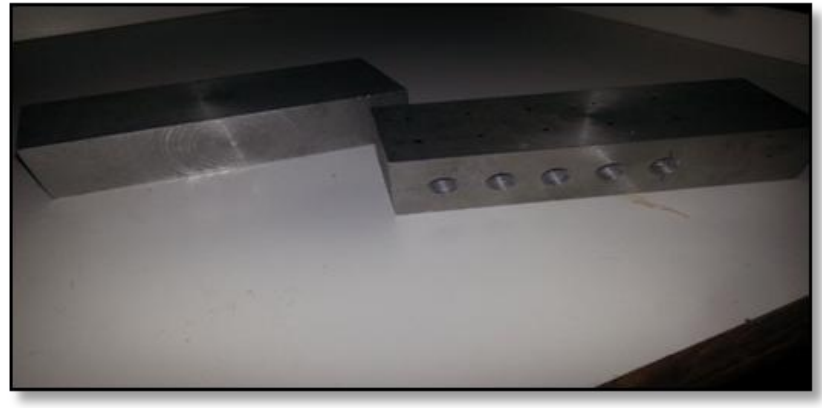

\section{b. Fin Effectiveness:}

Fig.1: Solid and perforated fins

Fins are used to enhance heat transfer, and the use of fins on a surface cannot be recommended unless the enhancement in heat transfer justifies the added cost and complexity associated with the fins. In fact, there is no assurance that adding fins on a surface will enhance heat transfer. The performance of the fins is judged on the basis of the enhancement in heat transfer relative to the no-fin case. The performance of fins expressed in terms of the fin effectiveness defined as

$$
\varepsilon_{f i n}=\frac{\phi_{f i n}}{\phi_{\text {nofin }}}
$$

, $\dot{Q}_{\text {mo fin }}$ represents the rate of heat transfer from this area if no fins are attached to the surface. $\varepsilon_{f i n}=1$ indicates that the addition of fins to the surface does not affect heat transfer at all. That is, heat conducted to the fin through the base area is equal to the heat transferred from the same area to the surrounding medium. An effectiveness of fin $\varepsilon_{\text {fin }}<1$ indicates that the fin actually acts as insulation, slowing down the heat transfer from the surface. This situation can occur when fins made of low thermal conductivity materials are used. An effectiveness of $\varepsilon_{\text {fin }}>1$ indicates that fins are enhancing heat transfer from the surface, as they should. 


\section{c. Proper Length of a Fin:}

An important step in the design of a fin is the determination of the appropriate length of the fin once the fin material and the fin cross section are specified. For maximum heat transfer, the fin should be infinitely long. However, the temperature drops along the fin exponentially and reaches the environment temperature at some length. Designing such an "extra long" fin is out of the question since it results in material waste, excessive weight, and increased size and thus increased cost with no benefit in return. Fins that are so long that the temperature approaches the environment temperature cannot be recommended either since the little increase in heat transfer at the tip region cannot justify the large increase in the weight and cost. To get a sense of the proper length of a fin, we compare heat transfer from a fin of finite length to heat transfer from an infinitely long fin under the same conditions. The ratio of these two heat transfers is

$$
\frac{\dot{Q}_{\text {fin }}}{\dot{Q}_{\text {long fin }}}=\frac{\sqrt{h p k A_{c}}\left(T_{b}-T_{\infty}\right) \tanh m L}{\sqrt{h p k A_{c}}\left(T_{b}-T_{\infty}\right)}=\tanh m L
$$

Using a hand calculator, the values of tanh $\mathrm{mL}$ are evaluated for some values of $\mathrm{mL}$ and the results are given in Table.[5]

Table: The variation of heat transfer from a fin relative to that from an infinitely long fin.

\begin{tabular}{|c|c|}
\hline $\mathbf{m L}$ & $\frac{\dot{\boldsymbol{Q}}_{\text {fin }}}{\dot{\boldsymbol{Q}}_{\text {long fin }}}=\mathbf{t a n h} \mathbf{m L}$ \\
\hline 0.1 & 0.100 \\
\hline 0.2 & 0.197 \\
\hline 0.5 & 0.462 \\
\hline 1.0 & 0.762 \\
\hline 1.5 & 0.905 \\
\hline 2.0 & 0.964 \\
\hline 2.5 & 0.987 \\
\hline 3.0 & 0.995 \\
\hline 4.0 & 0.999 \\
\hline 5.0 & 1.000 \\
\hline
\end{tabular}

\section{d. Reynolds Number:}

The transition from laminar to turbulent flow depends on the surface geometry, surface roughness, flow velocity, surface temperature and type of fluid, among other things. After exhaustive experiments in the 1880s, Osborn Reynold discovered that the flow regime depends mainly on the ratio of the inertia forces to viscous forces in the fluid. This ratio is called the Reynolds number, which is dimensionless quantity, and is expressed for external flow as

$$
R e=\frac{\text { Inertia Forces }}{\text { Viscous Forces }}=\frac{V L_{c}}{v}=\frac{\rho V L_{c}}{\mu}
$$

Where $\mathrm{V}$ is the upstream velocity (equivalent to the free-stream velocity for a flat plate), $\mathrm{L}_{\mathrm{c}}$ is the characteristic length of the geometry, and $v=\mu / \rho$ is the kinematic viscosity of the fluid.

\section{e. Nusselt Number:}

In convection studies, it is common practice to nondimensionalize the governing equations and combines the variables, which group together into dimensionless numbers in order to reduce the number of total variables. It is also common practice to nondimensionalize the heat transfer coefficient $h$ with the Nusselt number, defined as

$$
N u=\frac{h L_{c}}{k}
$$


Where $\mathrm{k}$ is the thermal conductivity of the fluid and $\mathrm{L}_{\mathrm{c}}$ is the characteristic length. The Nusselt number is named after Wilhelm Nusselt, who made significant contribution to convective heat transfer in the first half of the twentieth century.

\section{f. Prandtl Number:}

The relative thickness of velocity and the thermal boundary layers is best described by dimensionless parameter Prandtl number, define as

$$
\operatorname{Pr}=\frac{\text { Molecular diffusivity of momentum }}{\text { Molecular diffusivity of heat }}=\frac{v}{\alpha}=\frac{\mu C_{p}}{k}
$$

g. Laminar Flow Over Flat Plates And Walls:

The local value of heat transfer coefficient is given by

Blasius equation

$$
\mathrm{Nu}_{\mathrm{x}}=\frac{h_{X} x}{k}=0.332 X\left(\operatorname{Re}_{\mathrm{x}}\right)^{0.5}(P r)^{0.333}
$$

The average value of heat transfer value coefficient is given by

Where,

$$
\mathrm{Nu}_{\mathrm{x}}=\frac{h_{X} x}{k}=0.332 X\left(\operatorname{Re}_{\mathrm{L}}\right)^{0.5}(P r)^{0.333}
$$

$$
\begin{aligned}
\operatorname{Re}_{\mathrm{x}} & =\frac{U x}{v}, \\
\operatorname{Re}_{\mathrm{L}} & =\frac{U L}{v}
\end{aligned}
$$

\section{h. Pressure Drag:}

The force a flowing fluid exerts on a body in the flow direction is called drag. The drag force depends on the pressure only and is independent of the wall shear since the shear stress in this case acts in the direction normal to the flow.The drag force depends on the density of the fluid, the upstream velocity V, and the size, shape, and orientation of the body, among other things. The drag characteristics of a body is represented by the dimensionless drag coefficient defined as

$$
C_{D}=\frac{2 F_{D}}{\rho A V^{2}}
$$

Where $\mathrm{A}$ is the frontal area (the area projected on a plane normal to the direction of flow e.g. A=LD) for blunt bodies (bodies that tends to block the flow). The drag coefficient is primarily a function of the shape of the body, but it may also depends on the Reynolds number and the surface roughness.

\section{Experimental Setup}

In this experiment, three fins are used one is without perforation and remaining fins are perforated. Fins have $10 \mathrm{~cm}$ length, $5 \mathrm{~cm}$ width and $3 \mathrm{~cm}$ thickness. One fin is perforated with $6 \mathrm{~mm}$ diameter of circular hole and other is $9 \mathrm{~mm}$ of circular hole. Fins are made of pure aluminum with thermal conductivity of $237 \mathrm{~W} / \mathrm{mK}$ by casting process with the help of wood pattern. Fins are heated by electrical banned heater which is made up of ceramic with thermal conductivity $150 \mathrm{~W} / \mathrm{mK}$ and of rectangular shape. Heater works on $230 \mathrm{~V}, 50 \mathrm{~Hz}$ and 600 watts single phase. Readings of heater measured in the form of voltage and current by digital voltmeter and digital ammeter. The heat transfer rate is calculated by multiplying the voltage and current. Blower is a device used to increase the velocity and pressure of air and it is used to forced convection heat transfer to increase the convective heat transfer rate. It is operated on suction mode. Speed of blower is constant that is $2800 \mathrm{rpm}$ and discharge can be varied by a cork provided at top of discharge pipe. Blower is fitted to left side of fins at a distance of $50 \mathrm{~cm}$ and forced air is passed through fins hence forced convection takes place and heat is dissipated. There will be 10 thermocouple used to measure the surface temperature of each fins and reading for these thermocouple is displayed on the digital temperature indicator. Manometer is a device used for measuring the pressure at a point in a fluid by balancing the column of fluid by another column of fluid. It is used to measure the pressure in pipes and channels. A tunnel of rectangular shape has dimension $15 * 10 \mathrm{~cm}^{2}$ and length $80 \mathrm{~cm}$ is placed on the table and fins with thermocouples are placed inside tunnel. 


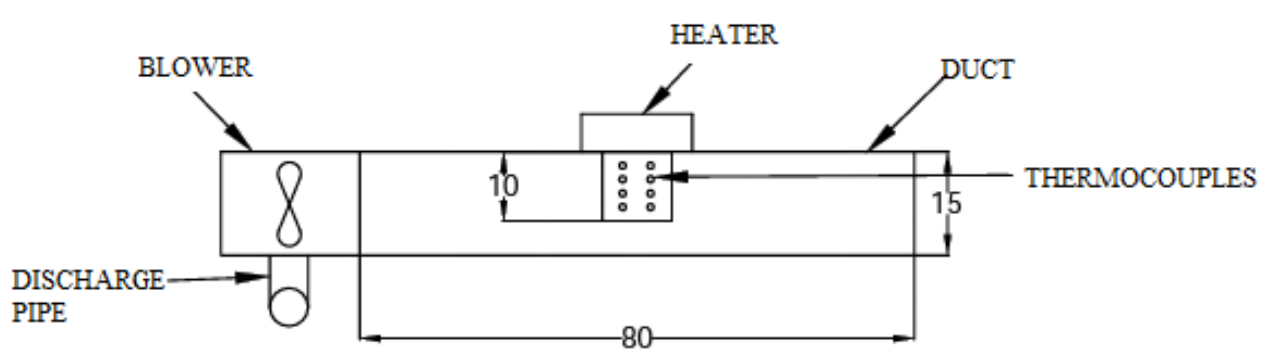

Fig.2: Setup Top view

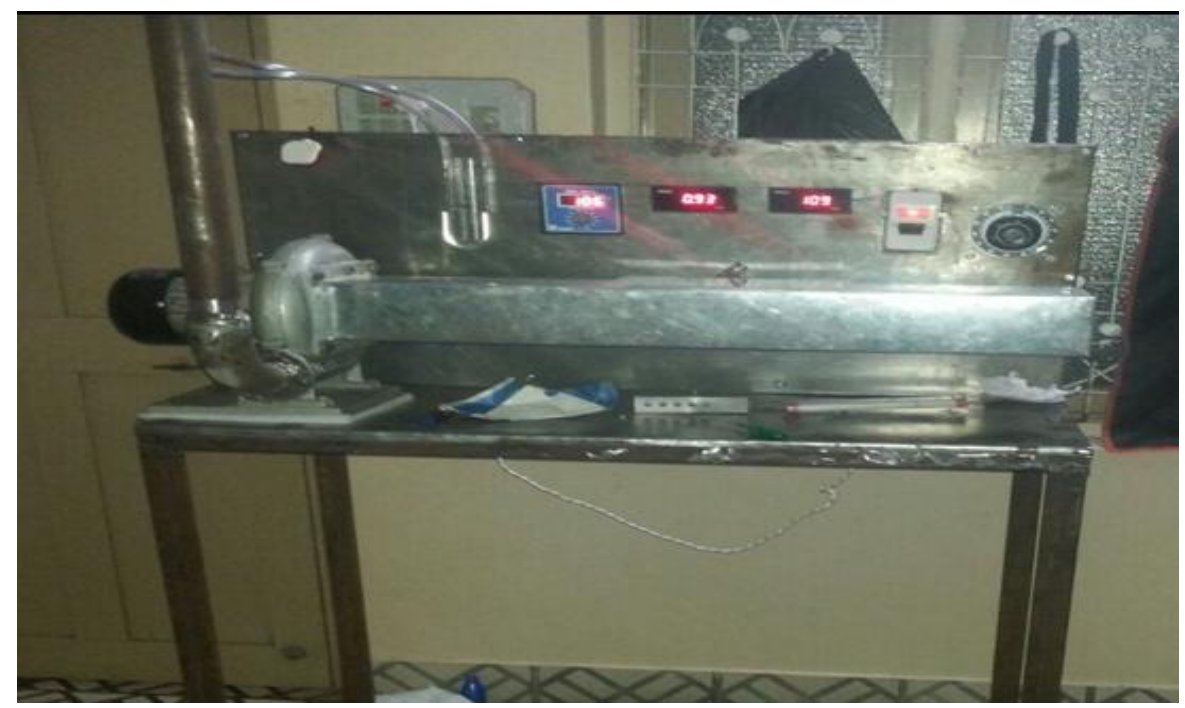

Fig.3: Setup Front view

\section{Results And Discussion}

This experiment of convective heat transfer which is performed on three fins and carried out for different Reynolds number under laminar flow conditions with same input heat supplied condition.

\section{Effects of Reynolds number on Convective Heat Transfer Coefficient:}

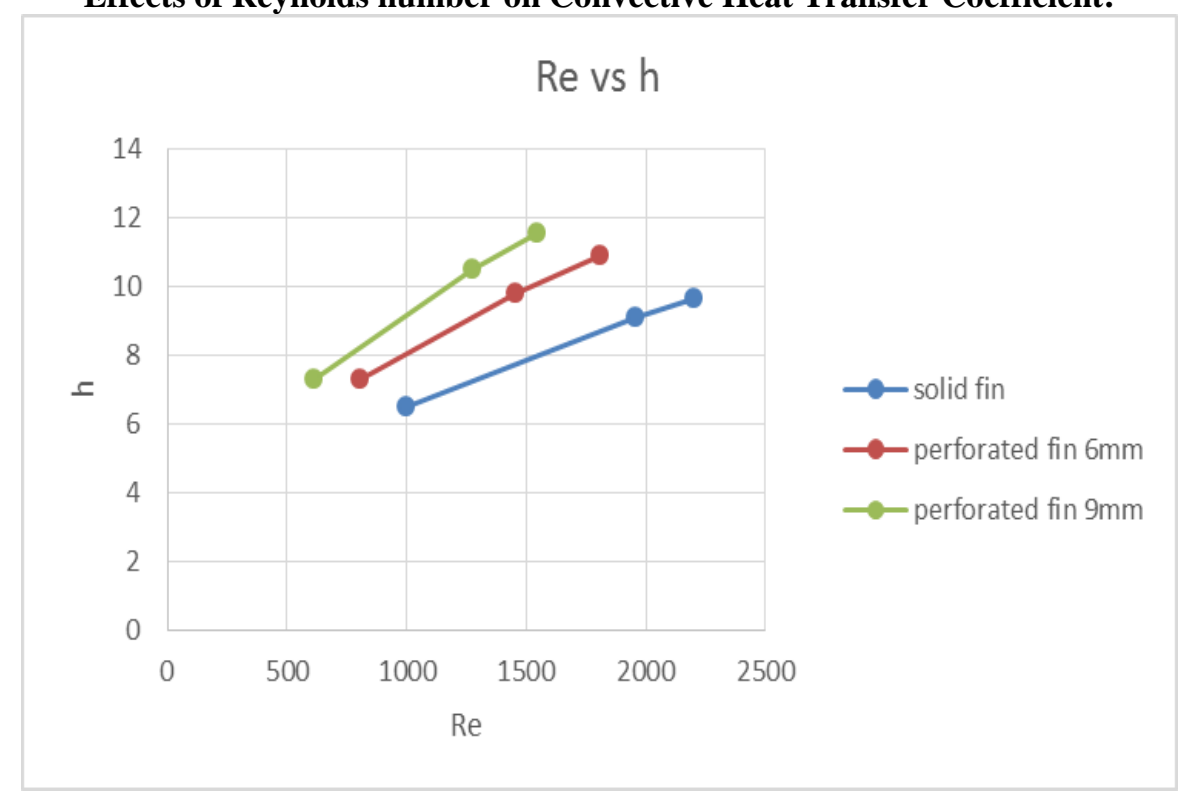

Fig.4: Reynolds number vs convective heat transfer coefficient 
From fig.4, It is clear that the perforated fin have higher convective heat transfer coefficient compare to solid fin. And convective heat transfer coefficient increases by increases the diameter of perforation. It is found that there is a significant rise of heat transfer coefficient values with increasing Reynolds number.

\section{Effects of Reynolds number on Effectiveness:}

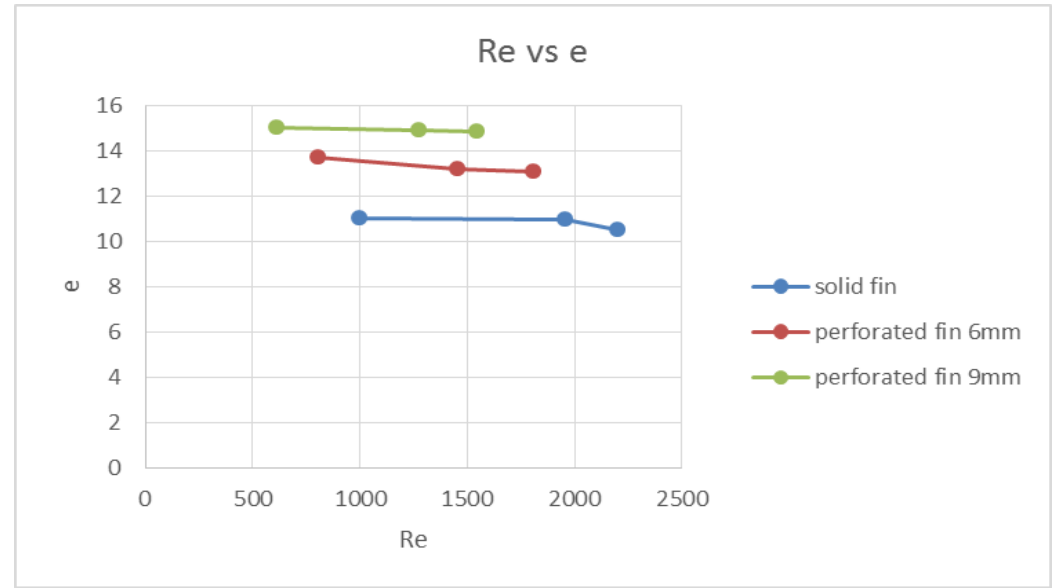

Fig.5: Reynolds number vs Effectiveness

From fig.5, it is clear that the effectiveness is independent on reynolds number but it increases by increasing diameter of perforation. Graph shows that the large value of perforation has greater effectiveness which means that the higher heat transfer takes place.

\section{Effects of Reynolds number on Effectiveness:}

From fig.6, it is found that the pressure drop is directly proportional to Reynolds number. And from graph it is clear that the pressure drop is less in perforated fin and greater in solid fin so from graph it is predicted that for perforated fin less pressure drag is there hence less fan power is required.

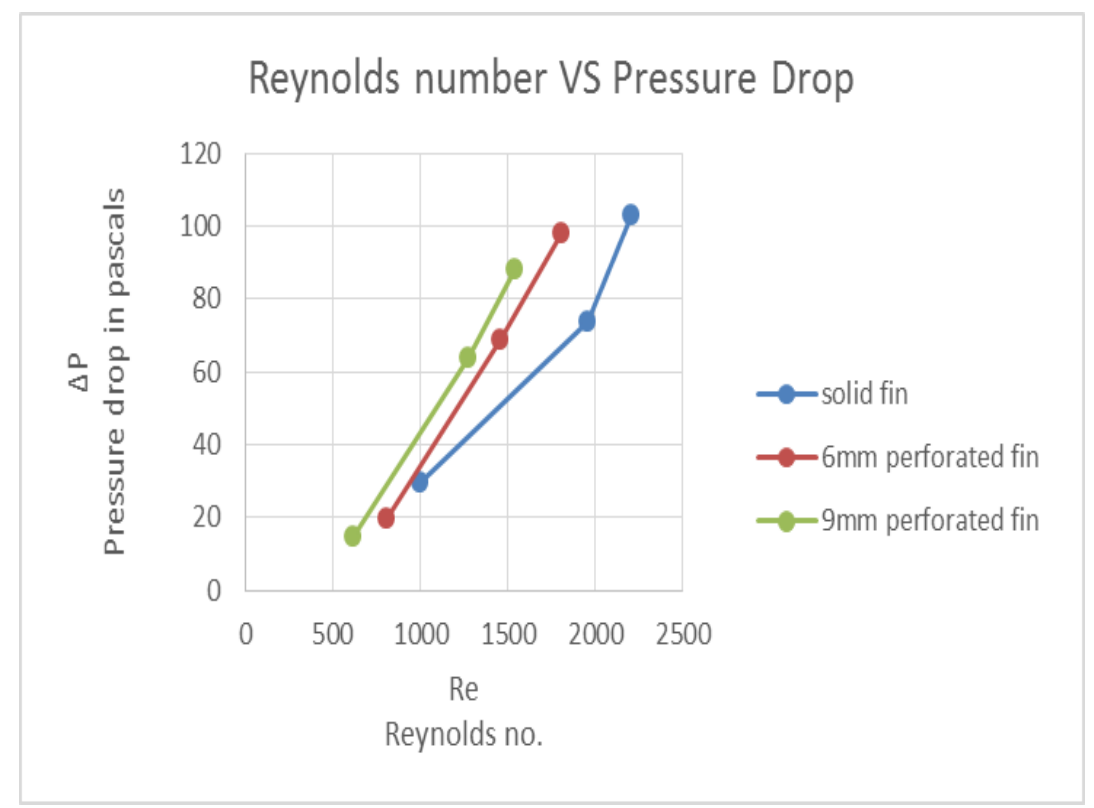

Fig.6: Reynolds number vs pressure drop

\section{Conclusion}

The previous study proves that the perforation is the latest method to enhance heat transfer. Perforation as well decrease the material required to manufacture fins. The perforation increases the convective area of heat transfer by virtue of that the rate of heat transfer increases and in this project as well we are going to practically 
prove the rate of heat enhancement by perforated fin as compared to non-perforated fin in forced convection as well investigating the effects of Reynolds number on fin with and without perforation.

\section{References}

[1]. Y. A. Cengel, A.J. Ghajar, Heat and Mass Transfer, (Fourth Edition, Mc Graw Hill)

[2]. Ehteshum, Mehedi, et al. Thermal and Hydraulic Performance Analysis of Rectangular Fin Arrays with Perforation Size and Number, Procedia Engineering 105,2015, 184-191.

[3]. Ismail, MdFarhad, et al. ,Numerical investigation of turbulent heat convection from solid and longitudinally perforated rectangular fins, Procedia Engineering 56 ,2013, 497-502.

[4]. M.R.Shaeri, M. Yaghoubi. Numerical analysis of turbulent convection heat transfer from an array of perforated fins." International Journal of Heat and Fluid Flow,2009,218-228.

[5]. Al-Damook, Amer, et al.,Computational design and optimisation of pin fin heat sinks with rectangular perforations, Applied Thermal Engineering 2016.

[6]. J. P. Holman and Souvik Bhattacharyya, Heat Transfer,( Tenth Edition, Mc Graw Hill). 